\title{
Differences in Lumbar Spine Load Due to Posture and Upper Limb External Load
}

\author{
Joanna Kamińska \\ Danuta Roman-Liu \\ Central Institute for Labour Protection - National Research Institute (CIOP-PIB), Poland
}

\author{
Tomasz Zagrajek \\ Pawel Borkowski
}

Institute of Aeronautics and Applied Mechanics, Warsaw University of Technology Warszawa, Poland

As the lumbar region of the spine is particularly predisposed to musculoskeletal disorders, the aim of this article was to assess lumbar spine load on the basis of an accurate model of this part of the body. The model was developed with the finite element method and the energy criterion for optimising muscle work. Computer calculations confirmed that stresses and compression forces in intervertebral discs increased with an increase in the load force and that they were significantly larger in the bent forwards posture than in the erect posture. This result clearly shows that lifting light objects and the erect posture are important elements in minimising spine load.

$$
\text { finite element model muscle co-operation spine load lumbar spine }
$$

\section{INTRODUCTION}

The sedentary posture dominates modern life. It prevails at work, at school, in transport and, last but not least, at home when relaxing. The consequences are felt by almost everyone. Although maintaining a sedentary posture does not require great physical effort, extended periods of an improper posture at work often lead to arthrosis, especially of the spine, which is painful [1].

An increasing number of spine diseases and disorders is a growing social problem. Methods of assessing the spine load, in particular load conditions, are limited and often require invasive tests $[2,3,4]$. As invasive tests should be avoided, other methods are used. Subjective tests are used to analyse musculoskeletal load; they can consist in, e.g., filling in questionnaires or marking maps of the human body to provide information on the perception of pain or discomfort [5]. Given that this information is qualitative, subjective tests are used either to initially assess a problem or to obtain an overview of an epidemiological study. However, they cannot be used to analyse in detail static load mechanisms, hence they are treated as a method supporting studies of a different type.

Musculoskeletal load can also be directly assessed at the workstand. The NIOSH OWAS method is an example $[6,7,8]$. Direct assessment makes it possible to assess how strenuous work is by determining load indicators and taking

This publication has been prepared on the basis of the results of a research task carried out within the scope of the statutory activity of the Central Institute for Labour Protection - National Research Institute (project IV-14) partly supported by the Ministry of Science.

Correspondence and requests for offprints should be sent to Joanna Kamińska, CIOP-PIB, ul. Czerniakowska 16, 00-701 Warszawa, Poland. E-mail: <jozab@ ciop.pl>. 
into account individual work tasks. Yet it does not consider such factors as workers' anthropometrical differences, performance of work by several persons, performance of more complex activities and, finally, it is not precise.

Computer modelling is increasingly used in assessing musculoskeletal load. The accuracy of the computer-generated human body model depends on the modelling techniques used. Computer models developed with the finite element method (FEM) are the most precise. FEM is generally used for solving technical issues, e.g., for simulating machines, buildings, and frequently for modelling the human musculoskeletal system. FEM makes it possible to obtain highly accurate results and to model, with considerable ease, such complex systems as the human body. This method complements and confirms the results of experimental studies; it can be used to analyse human body load without external loads that could be hazardous for subjects or impossible in an experimental study. Biomechanical modelling of the spine includes analysing spinal loading $[9,10,11,12]$, stability $[11,13,14]$, dynamics of injury $[15,16]$ and surgery analysis $[17,18]$. The reliability of the assessment of musculoskeletal load conducted with computer modelling depends on the accuracy of the human model on the one hand, and on the applied muscle optimising procedure, on the other.

As the lumbar region of the spine is particularly predisposed to musculoskeletal disorders, the objective of the analysis in this article was to assess the spine load in its lumbar region on the basis of an accurate model of this part of the body. The model was developed with FEM and the energy criterion for optimising muscle work. This model helped to determine the relationship between postures of the spine, upper limb load and forces developed by the modelled muscles as well as stress in intervertebral discs.

\section{COMPUTER MODEL}

\subsection{Model of the Trunk}

FEM and ANSYS version 8.0 were used to develop a three-dimensional model of the musculoskeletal system of the human trunk; the complexity of its unique shape (especially the lumbar vertebrae) was taken into account $[9,10]$. The lumbar region of the spine was modelled in detail including the difference in structure among the lumbar vertebrae; whereas other elements of the trunk were imaged schematically as the model was designed for assessing the spine load in the lumbar region (Figure 1). The model consisted of

- five lumbar vertebrae;

- six intervertebral discs (Th12/L1-L5/S1 including annuli fibrosi and nuclei pulposi);

- part of the sacral bone with the upper edge of the pelvis;

- part of the trunk above the intervertebral disc Th12/L1, modelled as a lump of large rigidity;

- ligaments (anterior, posterior, yellow, interspinal, etc.);

- muscles (the intertransversarii, the interspinales, external and internal oblique muscles, the rectus abdominis).

Figure 1a is the overall view of the model, Figure $1 \mathrm{~b}$ is the lumbar region of the spine and the upper edge of the pelvis. The model was divided into three-dimensional (bones and intervertebral discs) and tensional (muscles) finite elements as well as two-dimensional elements (ligaments).

Table 1 illustrates how mechanical properties were attributed to each element. The difference in rigidity between the osseous elements and the spinal discs of the human body is considerable $[10,19,20,21,22]$. Values which apparently represent the qualities of the elements of the spine most accurately were accepted as a result of the analysis.

The magnitude of the finite elements depends on the complexity of the modelled regions. The lumbar region of the spine was divided into finite elements a few times smaller than the elements of the upper part of the trunk. The model was 
(a)

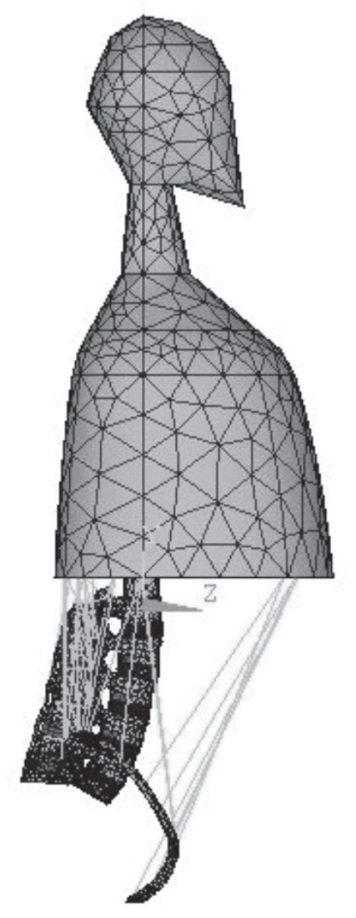

(b)

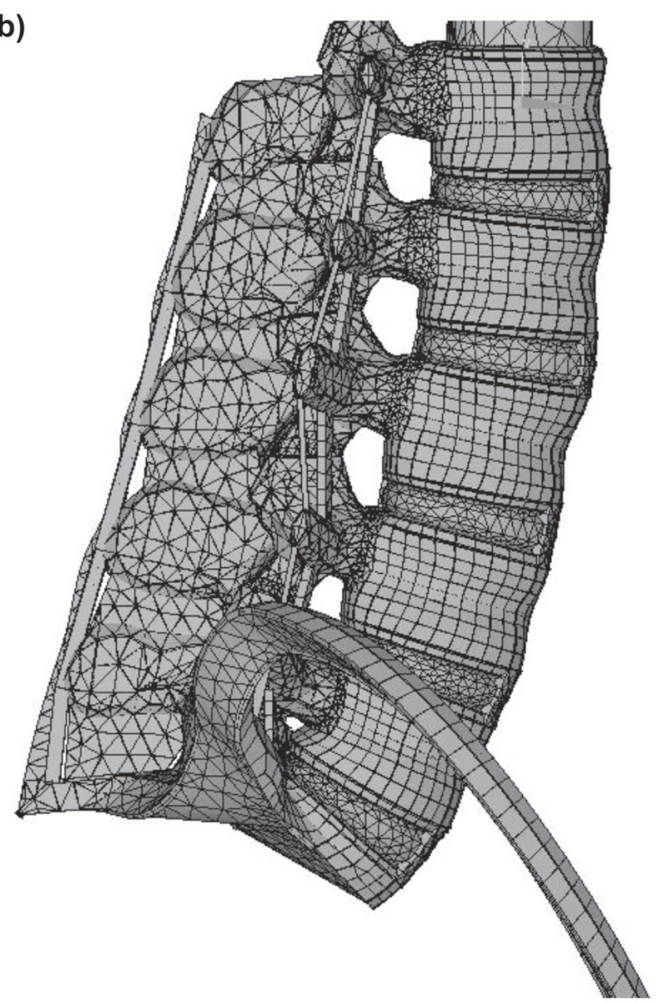

Figure 1. Model of the trunk: (a) side view, (b) the lumbar region of the spine and the upper edge of the pelvis.

immobilised in the lower part of the pelvis and the sacral bone. Selected nodes were deprived of all degrees of freedom.

TABLE 1. Mechanical Properties of the Elements of the Model

\begin{tabular}{|c|c|c|}
\hline Element & $\begin{array}{c}\text { Young's } \\
\text { Modulus (MPa) }\end{array}$ & $\begin{array}{c}\text { Poisson's } \\
\text { Ratio } \\
\end{array}$ \\
\hline Compact bones & 12000 & .300 \\
\hline Spongy bones & 2000 & .400 \\
\hline $\begin{array}{l}\text { Annulus fibrosus of the } \\
\text { disc }\end{array}$ & 10 & .350 \\
\hline $\begin{array}{l}\text { Nucleus pulposus of } \\
\text { the disc }\end{array}$ & 0.012 & .499 \\
\hline Ligaments & 10 & .350 \\
\hline Muscles & 10 & .350 \\
\hline $\begin{array}{l}\text { Trunk (above the L1 } \\
\text { vertebra) }\end{array}$ & 12000 & .350 \\
\hline
\end{tabular}

\subsection{Criteria of Muscle Optimisation}

To correctly model the human body and to define tensions in bones, tendons or intervertebral discs, it is necessary to apply muscle forces optimisation criteria that make it possible to calculate forces developed by individual muscles.
In literature there are examples of how the problem of co-operation between work muscles can be solved [21, 22, 23]. Optimising criteria are used to imitate the principles on which muscles co-operate. It can be assumed that they fulfil the role of the nervous system steering the muscles.

Originally, optimising criteria were linear, now they are much more complex. However, they are not free from inconsistencies and contradictions. The first attempts to solve the issue of muscle participation with optimised methods used linear indicators of quality, e.g., the sum of stresses in individual muscles was minimised [24, 25].

Nonlinear criteria are much more common now; e.g., Pedotti, Krishnan and Stark used a nonlinear criterion in which the sum of square stresses for individual muscle functional units was minimised [26]. In the criterion used by Ezquerro, Simón, Prado, et al., the sum of stresses raised to the third power was minimised [22]. Siemieński's soft saturation criterion predicted a nonlinear relationship between muscle forces and their reaching, jointly and smoothly, the condition of saturation [27]. The 
energy criterion is one of the best optimised criteria as it makes imitating real processes possible [21, 27, 28]. It assumes that the modelled system will perform tasks with the minimum amount of work, so it provides the most reliable results in the process of modelling the human body.

Models of the human motor system, most frequent in ergonomics, make it possible to define reaction forces in joints in static or dynamic conditions [29, 30]. Only in very few of them is it possible to define forces developed by individual muscles, which is indispensable to correctly assess distribution of stress in the human body. Chaffin and Andersson's model, which takes into account some muscles of the back, is an example [30]. Seireg and Arvicar proposed a more complex and anatomically accurate human model [25]. It included almost all bones, articuli and muscles. However, in both cases a linear optimising procedure was used to determine forces developed by muscles.

There are few human body models that imitate the precise geometry of a healthy musculoskeletal system of the human spine, use a realistic optimising criterion for muscle work and make it possible to analyse the impact of external load on stress in component parts of the model (muscles and intervertebral discs). Nachemson and Elfstrom's experimental study made it possible to determine changes in tension in intervertebral discs for various body postures [2]. The results showed that body posture, and for a sedentary posture a supported back and the type of the upper limb load, greatly influenced the load of the lumbar region of the spine. However, the study selected body postures only and involved invasive tests.

The accurate model of the human trunk discussed here assumes that the modelled muscles work in accordance with the following energy criterion:

$$
E N E=\frac{1}{2} \cdot \sum_{i=1}^{m} \frac{l_{i} F_{i}^{2}}{E_{i} A_{i}}=\min ,
$$

where ENE-optimised objective function; $i=1, \ldots, m$-index referring to consecutive muscle functional unit; $m$-total number of muscle functional units; $F_{i}$ - force (active and passive) developed by $i$-th muscle (independent variable); $A_{i}$-average physiological crosssection of $i$-th muscle; $l_{i}$-length of $i$-th muscle.

In comparison to other human body models $[19,22]$, this model is complemented with abdominal muscles; not only the spinal column is considered. Forces developed by abdominal muscles play a significant role in maintaining balance and impact the spine load which is a counterbalance to the muscles of the back. The muscles of the back make it possible for the trunk to assume the bent backwards posture while abdominal muscles work when the trunk bends forwards. Erect posture is possible because of the balance between forces developed by the muscles of the back and those of the abdomen.

In the next part of the analysis of muscle load, the interspinous muscle was selected (muscle functional units 7-12) as the most powerful one among the modelled muscles of the back; in the model it acts as erector spinae (Table 2). Abdominal muscle load was also analysed: the external oblique muscle (muscle functional units 37-39), the internal oblique muscle (muscle functional units 40-41) and the rectus abdominis (muscle functional units 42-44) (Table 2).

\section{TABLE 2. Muscles in the Model}

\begin{tabular}{lc}
\hline Muscle & Functional Units \\
\hline Intertransversarii & $1-6$ \\
Interspinous & $7-12$ \\
Transversospinale & $13-31$ \\
Latissimus dorsi & $32-36$ \\
External oblique & $37-39$ \\
Internal oblique & $40-41$ \\
Rectus abdominis & $42-44$ \\
\hline
\end{tabular}

\section{RESULTS}

The model was used to analyse the impact of the back posture and the load on the upper limbs on stress in intervertebral discs and in the muscles of the abdomen and the back. The simulation 
developed to maintain an object of varied mass at the chest level was conducted with three body postures: $20^{\circ}$ bent forward, erect and $20^{\circ}$ bent backward with an unsupported back, and various values of force $(0,50,100,200 \mathrm{~N})$. The mass of the object ranged from 5 to $20 \mathrm{~kg}$, depending on the external force.

The results of the calculation include forces developed by the muscles, the minimum value of energy required to maintain an individual posture while imposing an external load (the value of the $E N E$ parameter) and stresses in intervertebral discs and lumbar vertebrae.

Figure 2 illustrates reduced stresses in intervertebral discs L1-L5 using an external load of $200 \mathrm{~N}$. They include the sheering and compressing stress component; that is why they are appropriate for interpreting the results. The values of reduced stress are lowest in disc L1/L2; they increase towards the bottom to reach maximum values in disc L5/S1. They are
0.4 MPa in disc L1/12 and go up to $1.9 \mathrm{MPa}$ in disc L5/S1. All calculation variants (various external load and modelled body posture) had the same tendencies.

Figure 3 shows the results of calculating stresses in the muscles of the back, exemplified by the interspinous muscle. The smallest stresses were noted in muscle functional unit 7 (located at the top), the largest in unit 12 (between the spinous processes of vertebrae L5 and S1). Both stresses and values of developed forces in those units increased from vertebrae L1 to S1. The first of the muscle functional units of the interspinal muscle between the trunk and spinous process of vertebrae L1 (muscle functional unit 7) developed force of $\sim 100 \mathrm{~N}$ and between the spinous processes of vertebrae L5 and S1 force of $280 \mathrm{~N}$ (unit 12). The rising tendency of the stresses in the intervertebral discs and in the back muscles towards the bottom of the spine may signify that that part of the spine is most prone to disorders.

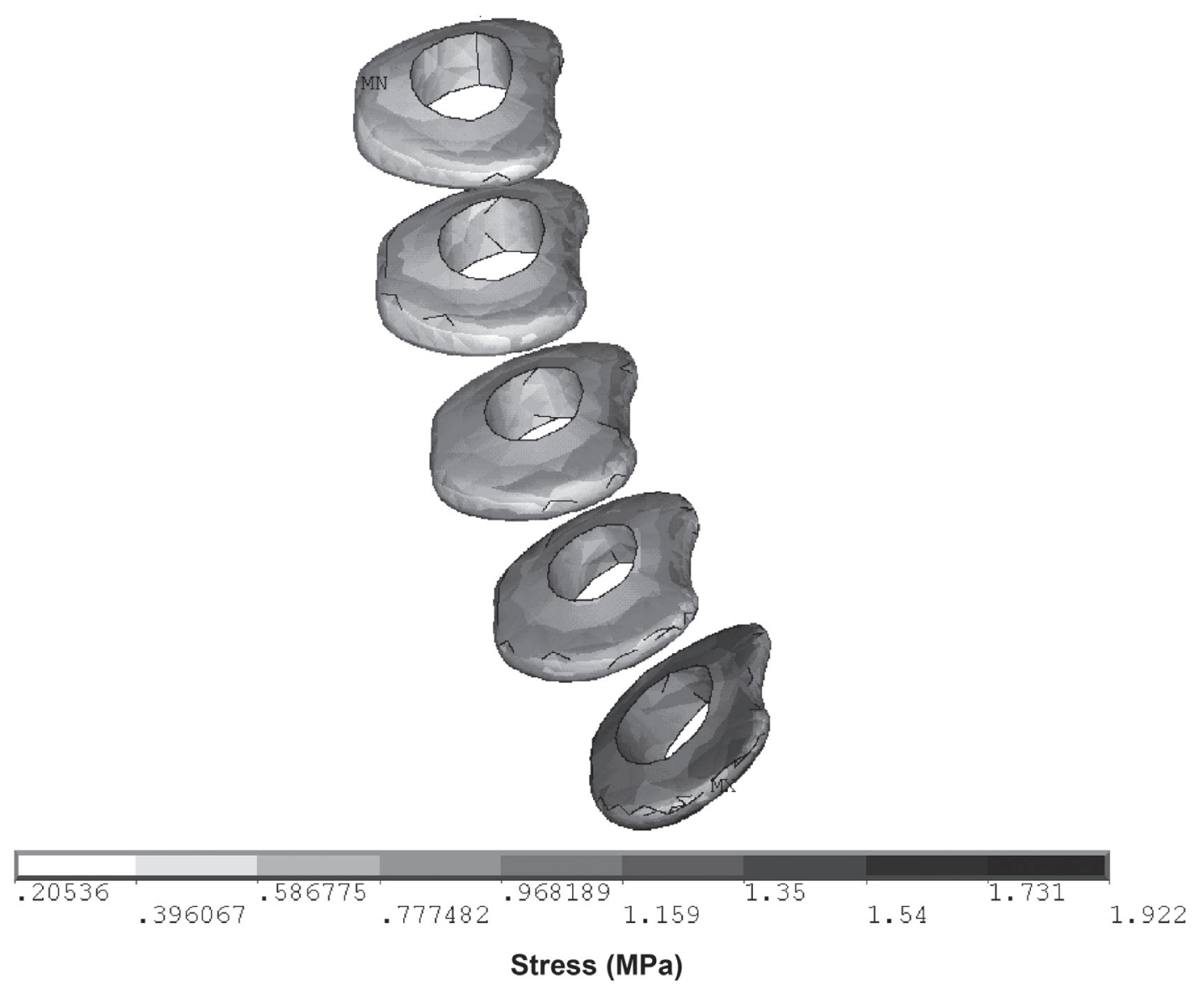

Figure 2. Reduced stress in intervertebral disc L1-L5 for a load of $200 \mathrm{~N}$. 


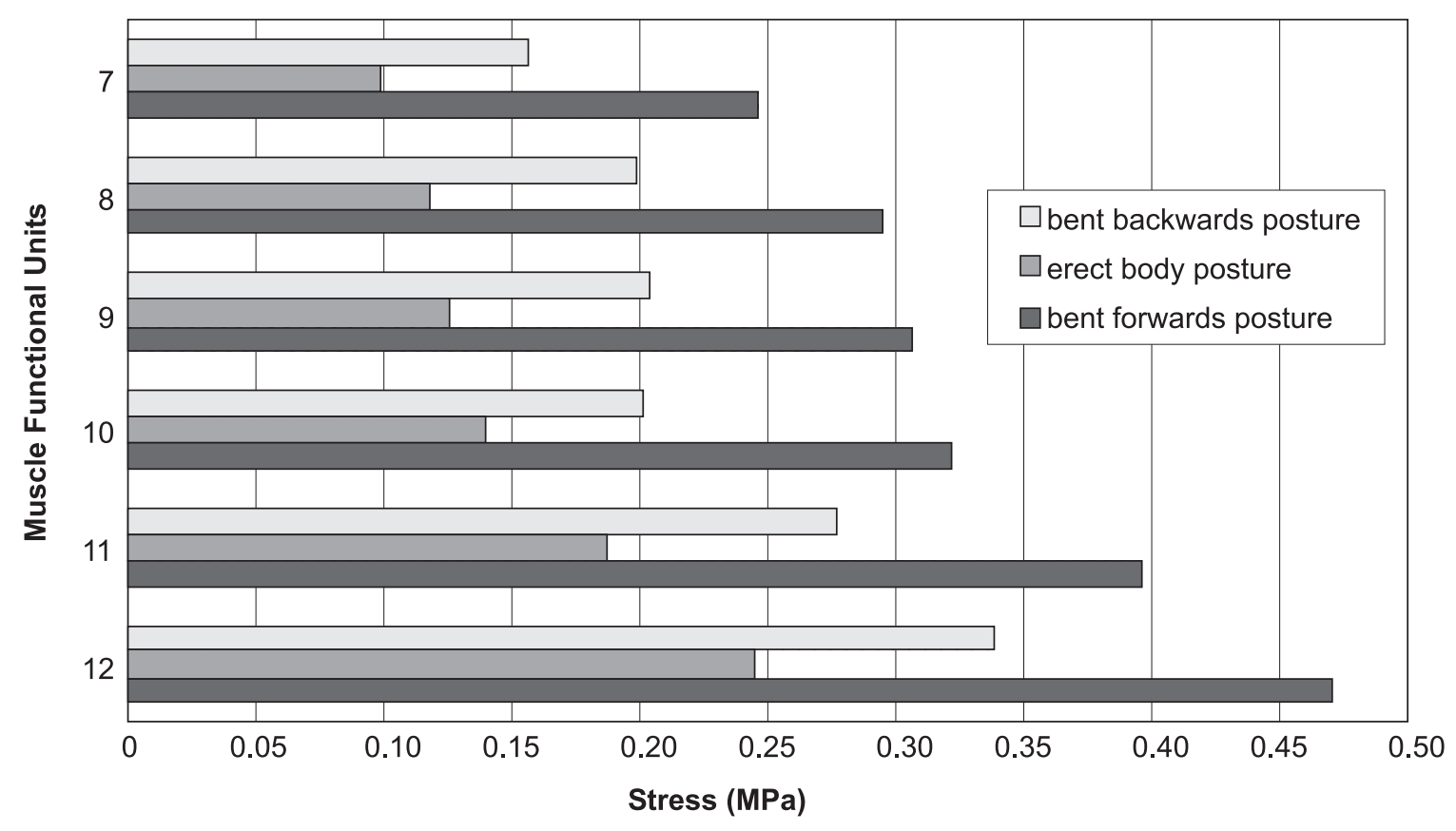

Figure 3. Values of stress in individual muscle functional units of the interspinous muscle with an external load of $200 \mathrm{~N}$. Notes. Muscle functional unit 7 is situated between the trunk and the spinous process of vertebae L1, unit 8 between the spinous processes of vertebrae L1 and L2, unit 9 between L2 and L3, unit 10 between L3 and L4, unit 11 between L4 and L5, unit 12 between L5 and S1.

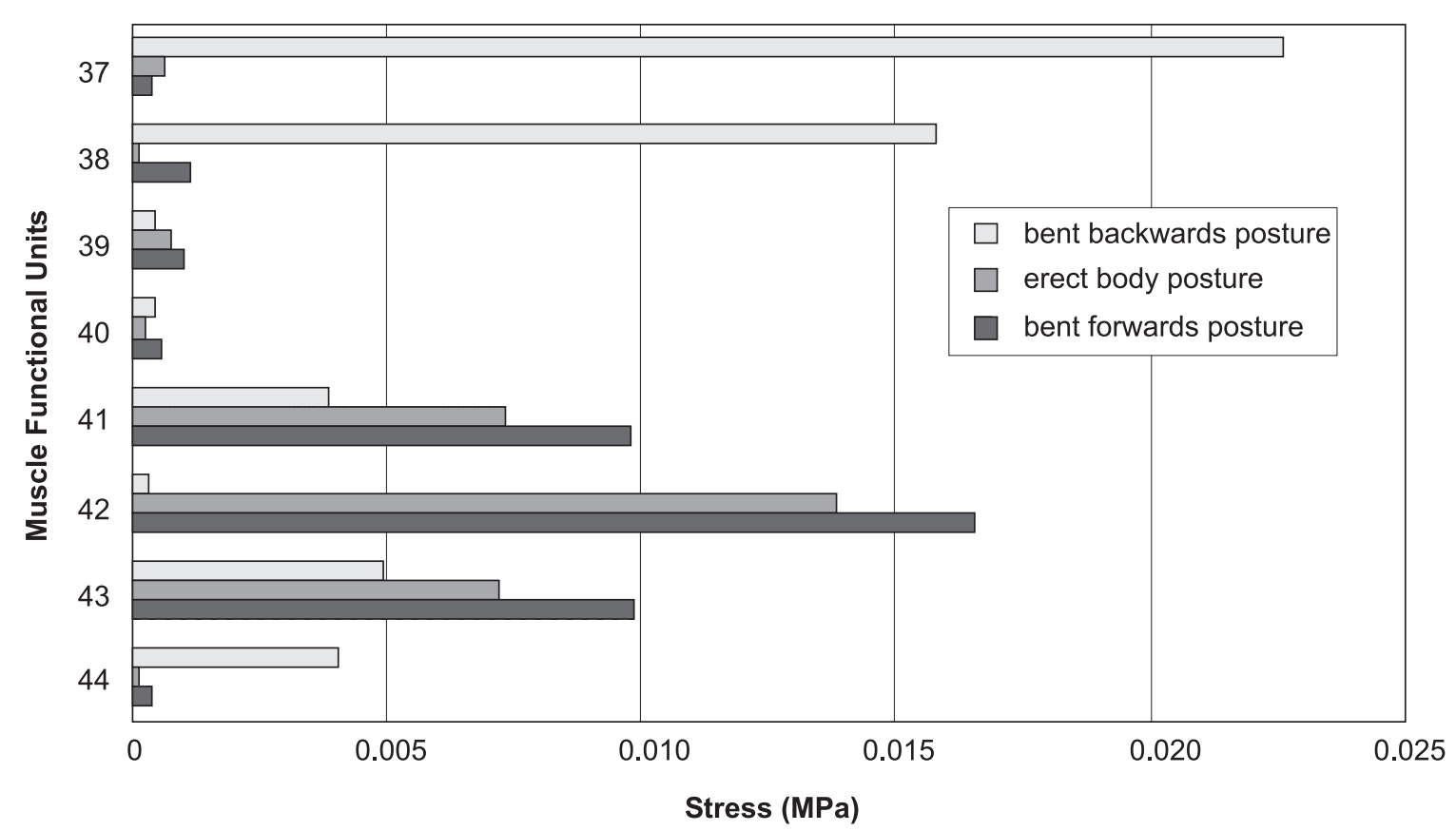

Figure 4. Values of stress in individual functional units of abdominal muscles with an external load of $200 \mathrm{~N}$. Notes. For muscle functional units of the abdomen see Table 2.

To maintain a balance and the modelled posture, it is necessary to take into account not only the back muscles but also abdominal muscles. Figure 4 presents calculations results for abdominal muscles stresses (the rectus abdominis, internal and external oblique muscles, muscle functional units 37-44). For all calculations variants, stresses values in 
abdominal muscles are considerably smaller than in muscles of the back and they reach maximum value of $\sim 0.02 \mathrm{MPa}$ (for calculations variant with the external load of $200 \mathrm{~N}$ ). Stresses in muscles of the back are several times bigger and for instance in the interspinous muscle they reach maximum amount of $0.46 \mathrm{MPa}$, also for the same, the heaviest calculation variant (Figure 3). External force was applied in such a way as to simulate lifting an object held in front at the chest level. Therefore such a distribution of forces between muscles of the back and muscles of the abdomen is justified. In an analysis of asymmetrical activities or a simulation of carrying an object on the back, e.g., abdominal muscles played a decisively greater role and considering them would be a sine qua non condition for a correct analysis of such an activity.

The parameter used to compare the internal load that has occurred as a result of the external load for all analysed variants of load (body posture and external load) is the amount of energy needed to perform a particular activity. Simulations made for the selected cases of external load showed that the value of the ENE coefficient in each variant of studies for a particular value of external force is the smallest for the erect posture. The value of this coefficient increases with an increase in the external load. However, this increase varies depending on the body posture taken. If no external force is applied, the most strenuous posture is a bent backwards posture. The value of ENE is then $30 \%$ greater than in the bent forwards posture. If the external load is bigger than $\sim 80 \mathrm{~N}$ the bent forwards posture requires the greatest amount of energy. For the most effortful variant (force of $200 \mathrm{~N}$ ), the value of ENE in the bent forwards posture is by $\sim 20 \%$ bigger than the bent backwards.

Body posture influences an increase in energy (Figure 5). The biggest impact on the spine load has the bent forwards posture, together with an increase in the external force, the energy value for this posture rises most rapidly. This means that, e.g., relocating objects in the bent forwards posture induces the highest consumption of energy, and can pose the greatest hazards leading to spine disorders.

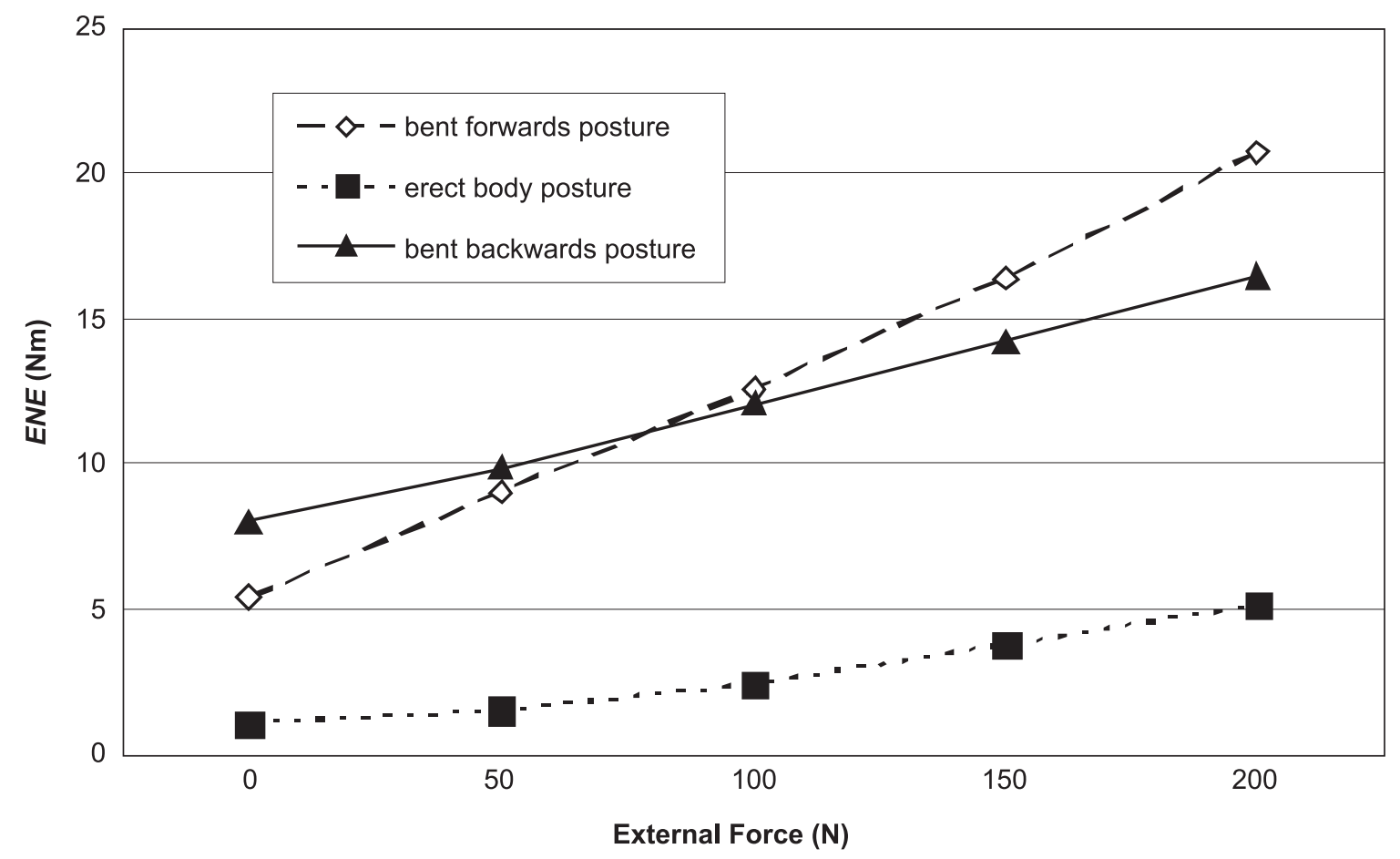

Figure 5. A comparison of the optimised objective function (ENE) for all variants of calculations. 


\section{DISCUSSION}

The developed three-dimensional model of the lumbar spine makes it possible to calculate stresses in vertebrae and intervertebral discs as well as forces developed by muscles considering external load, i.e., forces exerted by the upper limbs and the spine posture.

The model was used to analyse the impact of posture and the upper limb external load on the lumbar spine load. In the simulation developed to maintain an object of varied mass at the chest level, there were 15 variants of calculations made for three selected body posture and for five various values of the force applied.

A load of the human musculoskeletal system during work consists of three parameters: body posture, external load and time. In the design of this model the time factor was not taken into account, however, the impact of body posture and external force on the spine load is easily observable.

Stresses in intervertebral discs of the lumbar spine and forces developed by muscles of the back and muscles of the abdomen were analysed. For all calculation variants, the values of abdominal muscles stresses were considerably lower than of the muscle of the back, interspinalis and intertransversarii as an external force were applied in such a way so as to simulate lifting of an object held in front at the chest level. Such a distribution of forces between muscles of the back and of the abdomen was then expected, which confirms the need to include abdominal in human body models.

Values of forces developed by back muscles (interspinalis and intertransversarii) and values in intervertebral discs increase towards the bottom region of the lumbar spine from L1 to S1. Zagrajek made similar observations in his computer simulations [28]. Thus the L5/S1 lumbar spine is the section most exposed to occurrence of disorders. This phenomenon is irrespective of the posture.

Similar to the work of Chaffin and Andersson [30] and Marras, Granata, Davis et al. [32], stresses and compression forces in intervertebral discs increase together with an increase in the load force and are significantly larger in the bent forwards posture than in the in erect posture. This clearly shows that lifting objects of small mass and the erect posture are important elements minimising spine load.

The energy needed to perform a particular activity $(E N E)$ is the parameter that makes comparisons of individual variants of calculations possible. The value of this parameter varies depending on the assumed body posture. If no external force is at work, the erect posture is the least strenuous, and the most strenuous is the bent backwards posture. If the external load is larger than $80 \mathrm{~N}$, the bent forwards posture requires the largest amount of energy.

The value of the ENE parameter increases with an increase in external force. This increase can be seen for the bent forwards, bent backwards and erect postures. However, the body posture has an impact on the speed of the energy increase (the angle of inclination of the curve). The bent forwards posture has the largest impact on the spine load; the value of energy increases most rapidly with an increase in external force.

Nachemson and Elfstrom's experimental studies indicated that the type of sedentary posture and the type of activities performed with the upper limbs had an impact on the lumbar spine load [2]. Similar results were obtained in computer simulations. This means that the developed model can be used for calculating muscle forces and stresses in the lumbar spine that result from work in various body postures and with varying values of external force. Including internal abdominal pressure in a future model will make obtaining even greater precision of calculations possible.

\section{CONCLUSIONS}

The presented model of a human musculoskeletal system developed with FEM helps to analyse muscle forces of the spine and intervertebral discs load in an uninvasive way. Computer calculations confirmed that stresses and compression forces in intervertebral discs and muscle forces increase with an increase in the 
external load and are significantly larger in the bent forwards posture than in the erect posture.

\section{REFERENCES}

1. Corlett EN, Eklund AE, Johnson F. Method for measuring the load imposed on the back of a sitting person. Ergonomics. 1983;26:1064-76.

2. Nachemson AL, Elfstrom G. Intravital dynamic pressure measurements in lumbar discs. A study of common movements, maneuvers and exercises. Scand J Rehabil Med. 1970;1:1-40.

3. Nachemson AL. Disc pressure measurements. Spine (Phila Pa 1976). 1981; 6:93-7.

4. Adams MA, Dolan P. Recent advances in lumbar spinal mechanics and their clinical significance. Clin Biomech (Bristol, Avon). 1995;10(1):3-19.

5. Caffier G, Kössler F, Steinberg U. Assessments of relationship between musculoskeletal disorder and working conditions by a combination of questionnaire, clinical investigation, and task analysis. In: Problems and Progress in Assessing Physical Load and Musculoskeletal Disorders. Bremerhaven, Germany: Wirtschaftsverlag NW Verlag für neue Wissenschaft; 1996. p. 21-31.

6. Pizatella TJ, Putz-Anderson V, Bobick TG, McGlothlin JD, Waters TR. Understanding and evaluating manual handling injuries: NIOSH research studies. Ergonomics. 1992;35(9):945-53.

7. Kivi P, Mattila M. Analysis and improvement of work postures in the building industry: application of the computerised OWAS method. Appl Ergon. 1991;22:43-8.

8. Chung KM, Lee I, Kee D, Kim SH. A postural workload evaluation system based on a macro-postural classification. Hum Factors Ergon Manuf. 2002;12(3):267-77.

9. Kamińska J, Roman-Liu D, Zagrajek T, Borkowski P. Model kręgosłupa lędźwiowego czlowieka [The model of human lumbar spine]. Acta Bioeng Biomech. 2004;6 Suppl 1:77-81.

10. Kamińska J, Borkowski P, Roman-Liu D, Zagrajek T. Finite elements analysis of spine during computerised tasks. In: Proceedings of 11th International Conference on $\mathrm{Hu}$ man-Computer Interaction, vol. 1-Engineering Psychology, Health and Computer System Design [CD-ROM]. Mira Digital Publishing; 2005.

11. Dietrich M, Kędzior K, Miller K, Zagrajek T. Statics and stability of human spine under working conditions. In: Marras WS, Karwowski W, Smith JL, Pacholski L, editors. The ergonomics of manual work. London, UK: Taylor \& Francis; 1993. p. 147-50.

12. Gardner-Morse M, Stokes IAF. Structural behaviour of human lumbar spinal motion segments. J Biomech. 2004;37:205-12.

13. Arjmand N, Shirazi-Adl A. Model and in vivo studies on human trunk load partitioning and stability in isometric forward flexions. $\mathrm{J}$ Biomech. 2006;39:510-21.

14. Ivancic P, Cholewicki J, Radebold A. Effects of the abdominal belt on musclegenerated spinal stability and L4/L5 joint compression force. Ergonomics. 2002; 45(7):501-13.

15. Pankoke S, Hofmann J, Wölfel HP. Determination of vibration-related spinal loads by numerical simulation. Clin Biomech (Bristol, Avon). 2001;16 Suppl 1:S45-56.

16. Guo LX, Zhang M, Li JL, Zhang YM, Wang ZW, Teo EC. Influence prediction of tissue injury on frequency variations of the lumbar spine under vibration. OMICS. 2009;13(6):521-6.

17. Aubin CE, Petit Y, Stokes IA, Poulin F, Gardner-Morse M, Labelle H. Biomechanical modeling of posterior instrumentation of the scoliotic spine. Comput Methods Biomech Biomed Engin. 2003;6(1):27-32.

18. Dumas R, Lafage V, Lafon Y, Steib J-P, Mitton D, Skalli W. Finite element simulation of spinal deformities correction by in situ contouring technique. Comput Methods Biomech Biomed Engin. 2005; 8(5):331-7.

19. Borkowski P, Wymysłowski P, Kędzior K, Krzesiński G, Zagrajek T. Modelowanie numeryczne połączenia kość-sztuczny dysk w odcinku lędźwiowym kręgosłupa [Numerical modelling of the artificial discbone fusion in lumbar spine]. Acta Bioeng Biomech. 2003;5, Suppl 1:48-53. 
20. Będziński R. Biomechanika inżynierska. Zagadnienia wybrane [Biomechanical engineering. Selected topics]. Wrocław, Poland: Oficyna Wydawnicza Politechniki Wrocławskiej; 1997.

21. Panjabi M, White A III. Clinical Biomechanics of the spine. 2nd ed. Philadelphia, PA, USA: Lippincott Williams \& Wilkins; 1990.

22. Ezquerro F, Simón A, Prado M, Pérez A. Combination of finite element modeling and optimization for the study of lumbar spine biomechanics considering the 3D thorax-pelvis orientation. Med Eng Phys. 2004;26(1):11-22.

23. Siemieński A. Soft saturation, an idea for load sharing between muscles. Application to the study of human locomotion. In: Cappozzo A, Marchetti M, Tosi V, editors. Biolocomotion: a century of research using moving pictures (International Society of Biomechanics Series). Rome Italy: Promograph; 1992. p. 293-304.

24. Barbenel JC. The biomechanics of the temporomandibular joint: a theoretical study. J Biomech. 1972;5:251-6.

25. Seireg A, Arvicar R. Biomechanical analysis of the musculoskeletal structure for medicine and sport. New York, NY, USA: Hemisphere; 1989.

26. Pedotti A, Krishnan VV, Stark L. Optimization of muscle-force sequencing in human locomotion. Math Biosci. 1978; 38:57-76.
27. Siemieński A. Modelowanie i badanie współdziałania mięśni szkieletowych człowieka w warunkach dynamicznych na przykładzie kończyny dolnej [Modelling and analysis of human skeletal muscle co-operation under dynamic conditions, based on a lower limb]. Studia i monografie AWF we Wrocławiu. 1994;40:149-73.

28. Zagrajek T. Modelowanie biomechaniczne układu kręgosłupa metodą elementów skończonych [Biomechanical modelling of the spine using finite element method (FEM)]. Prace naukowe Mechanika 140. Warszawa, Poland: Wydawnictwa Politechniki Warszawskiej; 1990.

29. Kędzior K, Zagrajek T. A biomechanical model of the human musculoskeletal system. In: Morecki A, Waldron K, editors. Modelling and simulation of human and walking robot simulation. Wien, Austria: Springer; 1997. p. 125-152.

30. Chaffin DB, Andersson GBJ, editors. Occupational biomechanics. New York, NY, USA: Wiley; 1991.

31. Chaffin DB. Development of computerized human static strength simulation model for job design. Hum Factors Ergon Manuf. 1997;7(4):305-22.

32. Marras WS, Granata KP, Davis KG, Alread GW, Jorgensen M. Spine loading and probability of low back disorder risk as a function of box location on a pallet. Hum Factors Ergon Manuf. 1997;7(4):323-36. 